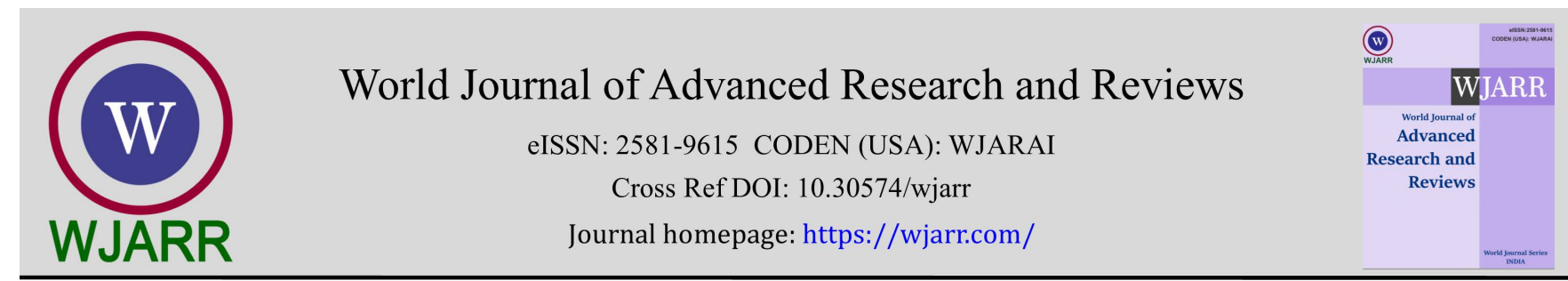

(REview ARTICLE)

Check for updates

\title{
An overview of the implications of covid-19 on economy, education and mental health
}

\author{
Qudsia Umaira Khan *, Kaenat Ahmed and Haleema Anwar \\ CMH Lahore Medical College and Institute of Dentistry, Lahore, Pakistan.
}

World Journal of Advanced Research and Reviews, 2021, 10(01), 210-217

Publication history: Received on 16 March 2021; revised on 17 April 2021; accepted on 19 April 2021

Article DOI: https://doi.org/10.30574/wjarr.2021.10.1.0168

\begin{abstract}
Coronavirus 2019 (COVID-19), a viral infection, has taken over the world. The infection was declared as a pandemic and a Public Health Emergency of International Concern in January 2020. Since then there have been lockdowns in numerous countries, causing multiple complications in not only the health sector but also in various aspects of life. COVID-19 has grid-locked the economy and is expected to lead to an economic crisis in the near future. The education system is also affected as examinations have been cancelled and classes are being given online which has decreased the quality. The lockdown has had a negative impact on human psychology. Amidst these circumstances, there are steps being taken to cope with these critical situations.
\end{abstract}

Since the outbreak of COVID-19 pandemic, a huge amount of formal and informal studies have appeared in literature. Given the diversity of media choices, the emerging knowledge has reached across the globe within very limited time. These studies, individually, have focused on almost all the aspects affected by the pandemic, like economy, healthcare, tourism, education etc.

This study by the authors provides a simplified overview of impacts of COVID-19 noted by various research studies. It is a useful concise account of COVID-19 effects in one-reading covering aspects like effects on healthcare \& healthcare workers, human behavior \& mental health, tourism, pollution and education.

Keywords: Coronavirus 2019; COVID-19; Economy; Education; Mental Health; Pandemic; Viral Infection

\section{Introduction}

The Coronavirus 2019 (COVID-19) pandemic has forced many businesses, academics, the health sector and the industry as a whole to reconsider and change their operations. It has put the world into a state of uncertainty, leaving countries incapable of controlling it. Besides non-availability of vaccination and medication, the reasons that contributed to difficulties in controlling are primarily the social reactions to this pandemic like fear of the unknown, panic due to uncertainty, indifference to the emerging situation and undue belief in fatalism [1].

Since the outbreak of the coronavirus pandemic at the start of the year 2020, governments across the world have been faced with the task of seeking a permanent solution to this deadly virus [2]. This newly discovered coronavirus was initially discovered in China, on 31 December 2019 [3]. Globally, total confirmed cases as of January 05, 2020 were $86,468,659$ all over the world [4]. This outbreak COVID 19 is distinctive due to the extent of emergency situations it has caused around the world [5].

\footnotetext{
${ }^{*}$ Corresponding author: Dr. Qudsia Umaira Khan

Assistant Professor of Physiology, CMH Lahore Medical College, Lahore, Pakistan.

Copyright (C) 2021 Author(s) retain the copyright of this article. This article is published under the terms of the Creative Commons Attribution Liscense 4.0.
} 
The worst epidemic in contemporary history was the 1918 Spanish flu which killed tens of millions. Today, an epidemic is likely to spread more rapidly as the world has become a global village [6]. World leaders have repeatedly stated that, at a global level, efforts have not been enough to prevent and contain the outbreak because of a lack of planning in most countries' healthcare systems. COVID-19 is known to be of zoonotic origin and the original source has been linked to a wet animal market in Wuhan, China [7]. In each country, the increase in cases of the catastrophic COVID-19 epidemic has been largely due to local transmissions. In Pakistan, the goal has been to keep people with symptoms at home and to practice social distancing if their condition does not require hospital-level care, in order to curb excessive demand. Figure-1 illustrates that after 76 days of lockdown, the curve of reported cases in China flattened and the situation started to return to normal.

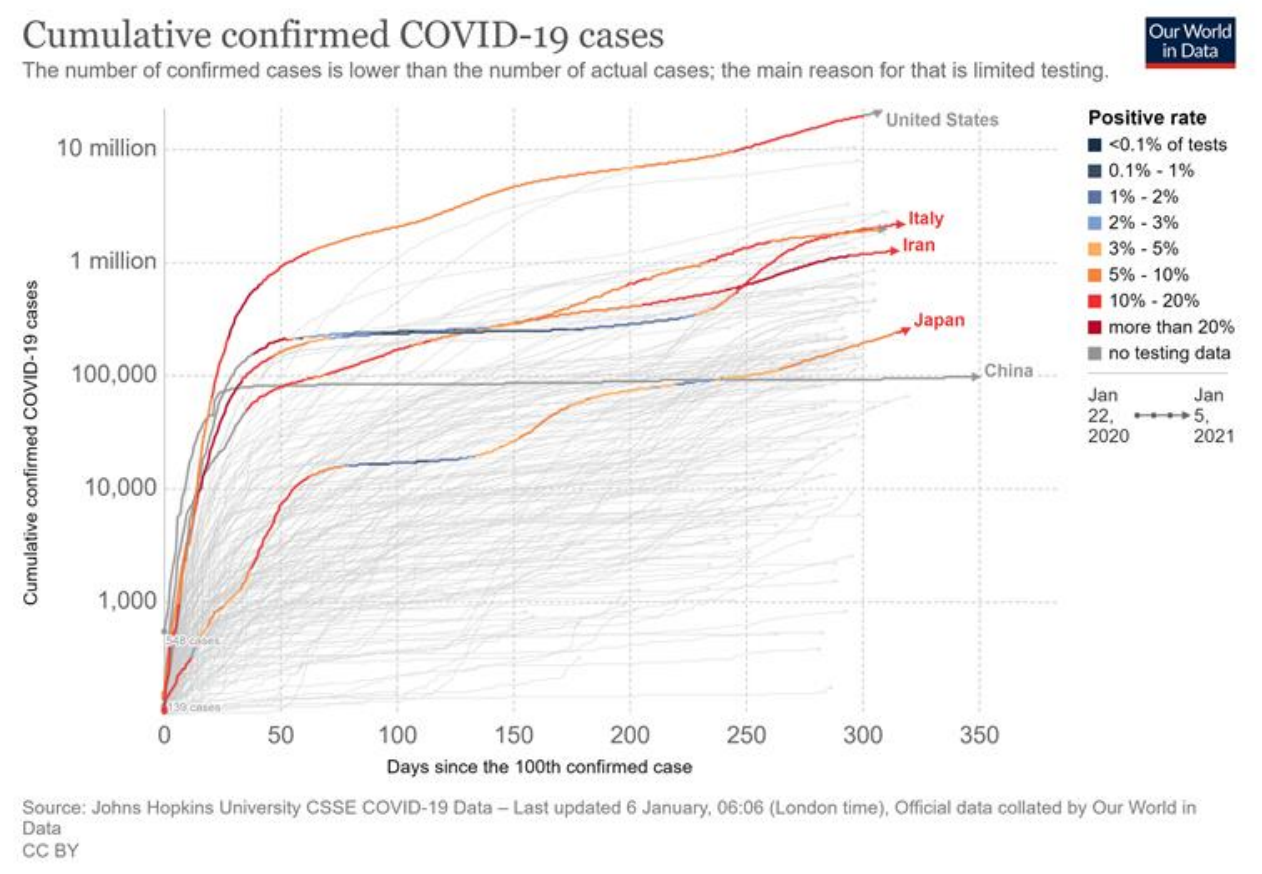

Figure 1 Epidemic Curve of Confirmed COVID-19 [8]

This study by the authors provides a simplified overview of impacts of COVID-19, noted by various research studies, in one-reading covering aspects like effects on healthcare \& healthcare workers, human behavior \& mental health, tourism, pollution and education.

\section{Discussion}

\subsection{Impact of Covid-19 on Health and Economy}

COVID-19 has been the cause of the worldwide health crisis and economic recession. In the past, healthcare was largely unaffected by recessions. Certain countries like African countries that already have a poor health care system have suffered a lot due to COVID 19. In China, good care was provided to all patients, whether time was critical or not [9]. Medical care demand has generally been catered for by available resources, whatever the situation may be. Bedford (2020) stated that the COVID-19 recession is different from other recessions as patients are being asked to stay at home to reduce the risk of the infection, thus affecting the economy as well.

In many places, the majority of the healthcare staff has been busy dealing with COVID-19 patients. There has been a tremendous decrease in other patients in the health care sector. Chandir, Siddiqi, Setayesh \& Khan (2020) have reported that the mean number of daily immunization visits in Karachi (Pakistan) decreased by 52.8\% (from 5184 to 2450 visits) during the first 6 weeks of lockdown compared with baseline [10]. A 70\% reduction of patients was reported in some primary healthcare sectors [11]. Clinical staff is suffering economically as well; some of their salaries have been reduced due to this pandemic [12]. A survey was conducted in Pakistan during March to April 2020. Participants were professionals of all private and public sector institutions. Results of the survey indicated that health professionals were overwhelmed and financially unstable due to COVID19 [13]. Unemployment in every field, including health care, is increasing day by day due to COVID-19 [14]. 
In the time of the COVID-19 pandemic, there has been a lot of change in the behavior of humans. People have been urged to stay at home even if they have any health-related problem other than COVID-19. Patients are hesitant to visit health care services due to the risk of transmission of this virus. This means deferring visits to clinics for common diseases. More telemedicine is being practiced to treat common diseases such as fever, cough and flu. According to statistical data, there were almost million visits to healthcare sectors before this pandemic which has since exceptionally reduced [15]. In New Zealand, the strategy applied to combat this virus was unique and different from many other countries. New Zealand adopted the "elimination strategy" which is bringing cases down to zero or near zero in a specific area. This proved to be more effective than partial lockdowns with the alleviation and termination of lockdown time in time [16]. Many health care workers throughout the COVID 19 pandemic have had mental stress, anxiety and fatigue. Some are suffering financially as well [17].

\subsubsection{Global Recession is Almost Inevitable}

The global recession seems probable, as well as the threat to developing countries. The impact of increased demand for specified items is projected to be greater than the recent limited supply. There will be instability, confusion, and panic purchasing. A substantial decline in demand of some items would lead to a forced closing of many businesses, eventually, cause soaring unemployment rates and, as a result, a further decrease in sales will direct the economy in a depressing loop [18].

\subsubsection{Tourism Industry among Hardest Hit}

With airline companies cutting their operations and tourists unable to travel, the tourism business has experienced financial losses. To seek control of the virus, authorities around the world have restricted their borders and airspace. In the past months before the start of the COVID-19 pandemic, there were 415,000 visits from China to the UK, with Chinese travellers also spending three times as much on an average UK visit at $£ 1,680$ each [19]. The resulting downturn in the travel and transport sector represents the degree of mass social alienation and the tightening of travel restrictions. An Australian airline decided they would not be doing international flights until March 2021 at the earliest [20].

According to the World Travel and Tourism Council, there are unprecedented 50 million workers at risk in the sector, of which 30 million are employees in Asia. Nicola (2020) states that one-tenth of global GDP is comprised of the travelling industry; a sluggish recovery may have significant repercussions [21]. In New Zealand, a strict lockdown (Alert level 4) was declared on 25th of March and by 15th May there were only 56 active cases. The New Zealand (2020) stated that the lockdown level in May moved to alert level 2. Queenstown's economy relies on tourism activities and thus its economy is most affected. Nicola (2020) stated that this impact is less for Wellington, for example, because of a lower degree of its dependence on tourism for economy. The task is to look for strategies to support tourism [22].

\subsubsection{Supply Chain Disruption}

The coronavirus epidemic has adversely impacted the network of suppliers which affects the world economic system. For example, China, one of the biggest exporters worldwide, has had a significant decline in exports between December 2019 and February 2020 [23]. This is depicted in Figure 2, this produces a rollover effect across various networks of suppliers.

As per the research of the Supply Management Centre in the US, "three-quarters of organizations record delays in their forwarding and logistics" [24]. According to this report, lead times for other US organizations have increased twice as much. Furthermore, resources and finished goods have been in shortage. All of which is compounded by the constraints on import and export on the ports all over nations. 


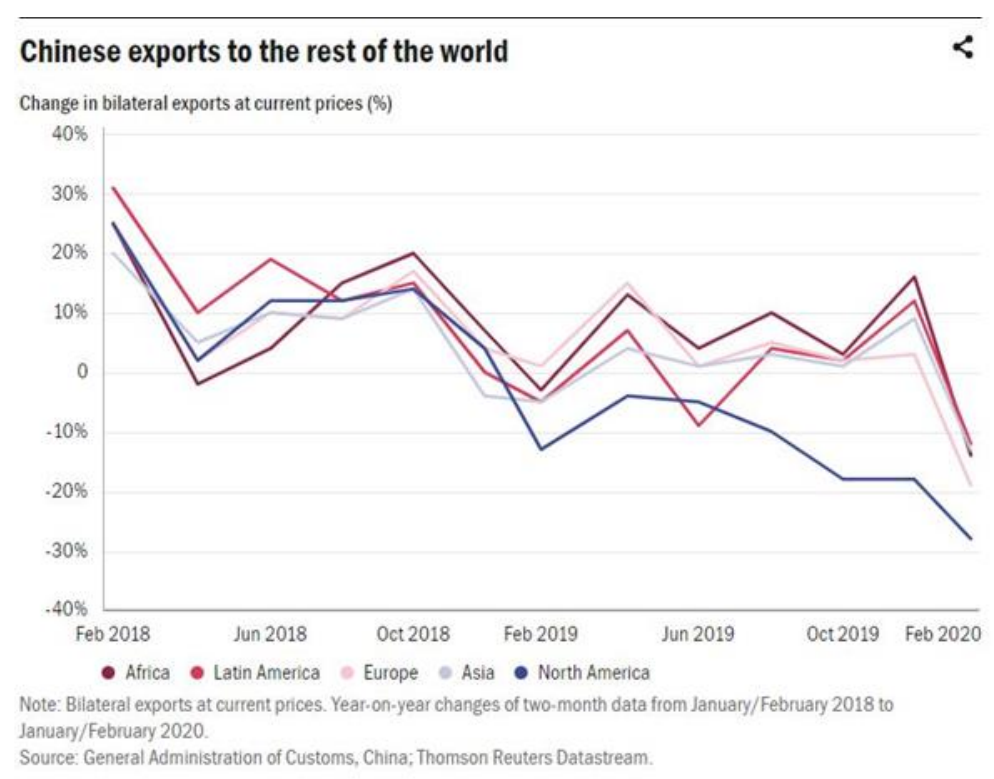

Figure 2 Imports from China [25]

The coronavirus has caused the distribution network to dwindle. It is clear that the initial downturn in production and trade seen in China would have a significant effect on other countries' supply chain, as most countries have already placed controls on movements to prevent the spread of the virus.

\subsection{Impact on Education}

During the catastrophic coronavirus epidemic, various universities from different nations not only delayed but also terminated plans regarding physical seminars, discussions, and other programs. Universities have taken extensive measures to discourage and protect all students and faculty from COVID-19. Therefore, teachers switched to digital platforms.

\subsubsection{Shift from Physical Classes to Online Classes}

The switch to the online streaming style encouraged many teachers and students worldwide to keep the education process sustained. Virtual education is not a novel method of delivery for every university. Many faculty members are being prepared to use only digital platform to teach or in combination with teaching in the classroom. However, there's always a risk that any faculty that isn't technology-friendly won't be able to teach on digital platforms [26]. The shift to a digital platform posed concerns about the faculty's ability to tackle current technology [27]. Furthermore, in-house workstations and information technology accessories are currently among the highest demand from parents, students, and teachers who are either taking online classes or giving them. The teachers have a daunting job to work from home. Most of the educational institutions still lack the infrastructure or tools to promote immediate online teaching [28]. Students face difficulties concerning laptop access, internet services. Another important problem that requires attention is the quality of online education.

\subsubsection{Examinations and Results}

Many educational institutions have postponed their end-of-semester exams, although online classes will continue to be evaluated continuously. The shift to teach using a digital medium from a physical classroom will have a huge effect on the examinations. While equipment was earlier utilized for conducting online classes, the examination dimension is still underdeveloped [29]. Teachers, along with students, are facing uncertainty regarding the process for handling impending tasks, assignments, and other ongoing evaluations. Faculty members need to adjust the form of assessment to complement the online environment. It is difficult to track how this is achieved digitally and to make sure that students are not able to cheat while attempting exams [30]. The pandemic also led to confusions in examination systems whereby institutions were not sure how to award justified marks without conducting regular examination. In the absence of proper examination, Cambridge University had to re-think its marks awarding strategy for their international examinations due to problems that aroused in initial system [31]. 


\subsubsection{International Students and Constraints for Travellers}

The coronavirus epidemic caused outages for airlines all over the world. Countries around the world are imposing constraints on traveling to contain the deadly virus, including for international students. Travellers who fly abroad run the risk of being infected. Overseas, students may have delayed returning to their home country due to problems related to budget. Meanwhile, students who have reached home are worried about the disruption in their studies. Sahu (2020) stated that some international students who have returned home might not have facilities such as stable internet connection, electricity, course material, and other equipment to continue with their studies.

\subsection{Impact of Covid-19 on Psychology and Behavior}

Currently, when we stand at the edge of the cliff, anticipating the psychological and behavioral effects from COVID-19, we are ill-prepared [32-33]. The WEF (World Economic Forum), the World Bank, and the World Health Organization have raised concerns about a mental health crisis. Indeed, mental illness currently accounts for the rising global burden of illness. Past research indicates that people on lower incomes experienced substantially higher levels of posttraumatic stress and depressive symptoms as they are majorly impacted by a temporary loss of income. A small number of people among us will contract the virus but it will affect many people mentally. From the instability of job cuts, layoffs, children's home education, isolation, loneliness, altered work schedules, increased domestic violence, and drug abuse, this may lead to traumatic experiences. At least $38 \%$ of Pakistanis live in multidimensional deprivation and more than a third below the poverty line, rendering the population especially vulnerable to trauma of mental health [34]. With no systems and processes to conduct timely data monitoring and an inevitable calamity upon us, fast yet accurate and effective decision-making is required to save the situation. Accurate and effective decision should be made by the government during this inevitable calamity.

Studies also have shown that people who have undergone severe acute respiratory syndrome (SARS) and other epidemics may have varying degrees of stress disorders, long after the disaster is over or after being treated and released from the hospital, suggesting that these individuals should not be overlooked [35].

According to the Federal Bureau of Investigations (2020), suicide rates have climbed up in the US since the inception of this pandemic [36]. Mohammed (2020) stated that social disconnectedness in times of uncertainty not only demoralizes people but also makes them feel useless, and out of hope about current events and upcoming happenings.

\subsection{Impact on the Environment}

Pollution has been a growing problem worldwide. It adversely affects the planet and is toxic to its inhabitants. Pollution damages health at all ages and even in utero [37-38]. The lungs are the primary victims of air pollution causing many diseases such as asthma, chronic obstructive pulmonary disease (COPD), lung cancer, and various respiratory infections. Air pollution also causes acute and chronic cardiopulmonary mortality [39].

Exposure to air pollution is a significant cause of mortality, giving rise to 3.2 million deaths each year. The World Health Organization has reported 4.6 million deaths per annum because of poor air quality secondary to pollution [40]. The air pollutants are particulate matter (PM), ozone, sulfur dioxide, nitrogen oxides (NO), carbon monoxide, and lead. Lead is detrimental to the brain's development [41]. Nitrogen dioxide (NO2) and carbon dioxide (CO2) are tracers for air pollution. NO2 is related to morbidity and mortality [42].

The lockdown has caused a decrease in traffic and industrial activities worldwide, leading to improvement in air quality. According to Gosens and Jotzo (2020), NASA has reported a reduction in NO2 emission first in Wuhan that has spread around the globe as countries declared lockdown. Having a look at China, where COVID-19 began, there has been a $30 \%$ decline in NO2 and 25\% decline in CO2. Griscom (2019) stated that CO2 concentration has been reduced by $6 \%$ worldwide.

This whole situation has led to a positive effect on the environment. It has reduced air pollution and improved air quality. There has been a reported decrease in temperature. Wholly the statistics indicate that the problem of air pollution is resolvable. A reduction in mortalities due to air pollution may be predicted in the future [43]. Lockdown has had a positive effect on air pollution, but the increased use of face masks has led to increased water pollution. The outbreak of the COVID-19 pandemic has increased the demand for medical services and protective equipment, giving rise to the procreation of infectious medical waste to increase promptly medical waste generation centers are being considered [44-45]. 


\section{Conclusion}

To conclude, air pollution is improving amid the COVID-19 pandemic. However, the detrimental impact of the pandemic on our global economy, education industry and, on psychological health cannot be overlooked. Government guidelines to work from home and to maintain social distancing have limited our social life. People are suffering from mental illness during crises, such as depression, anxiety, and suicidal ideation. Overall, countries need to invest in immediate and longterm policy, training, research, and service delivery activities to mitigate these negative effects.

\section{Compliance with ethical standards}

\section{Acknowledgments}

The authors appreciate and acknowledge the support provided by their colleagues in helping with writing and formatting this article.

\section{Disclosure of conflict of interest}

The authors declared no potential conflict of interest existing in this publication.

\section{References}

[1] Ahmed K. Patterns of Social Reactions to COVID-19 Pandemic; Reasons \& Proposed Ways to Overcome, Advanced Journal of Social Science. 2020; 7(1): 54-59.

[2] Nicola M, Alsafi Z, Sohrabi C, et al. The socio-economic implications of the coronavirus pandemic (COVID-19): A review, International Journal of Surgery. 2020; 78: 185-193.

[3] World Health Organization. WHO announces COVID-19 outbreak a pandemic. 2020.

[4] The Johns Hopkins University, Coronavirus Resource Center (2021, January 5). Data in motion. 2020.

[5] Anwar H, Khan QU. Pathology and therapeutics of COVID-19: A review. International Journal of Medical Students. 2020.

[6] Koonin LM. Novel coronavirus disease (COVID-19) outbreak: Now is the time to refresh pandemic plans. Journal of Business Continuity and Emergency Planning. 2020; 13(4): 1-15.

[7] Bedford J, Enria D, Giesecke J, et al. WHO Strategic and Technical Advisory Group for Infectious Hazards. COVID19: Towards controlling of a pandemic, Lancet. 2020; 395(10229): 1015-1018.

[8] Our World In Data (2021, January 5): Coronavirus (COVID-19) Cases. 2020.

[9] Liu Q, Luo D, Haase J, et al. The experiences of health-care providers during the COVID-19 crisis in China: A qualitative study. Lancet Global Health. 2020; 8(6): e790-e798.

[10] Chandir S, Siddiqi DA, Setayesh H, Khan A. J. Impact of COVID-19 Lockdown on Routine Immunization in Karachi, Pakistan, The Lancet - Public Health. 2020.

[11] Shadmi E, Chen Y, Dourado I, et al. Health equity and COVID-19: Global perspectives. International Journal for Equity in Health. 2020; 19(1): 104.

[12] Dubey S, Biswas P, Ghosh R, et al. Psychosocial impact of COVID-19: Diabetes Metabolic Syndrome. 2020; 14(5): 779-788.

[13] World Health Organization: Coronavirus disease (COVID-19) pandemic. 2020.

[14] Cutler D. How Will COVID-19 Affect the Health Care Economy? JAMA Health Forum. 2020; 323(22): $2237-8$.

[15] Garg S, Basu S, Rustagi R, et al. A Primary Health Care Facility Preparedness for Outpatient Service Provision During the COVID-19 Pandemic in India: Cross-Sectional Study, JMIR Public Health and Surveillance. 2020; 6(2): e19927.

[16] Cousins S. New Zealand eliminates COVID-19, Lancet. 2020; 395(10235): 14-74.

[17] Sethi BA, Sethi A, Ali S, et al. Impact of Coronavirus disease (COVID-19) pandemic on health professionals. Pakistan Journal of Medical Sciences. 2020; 36. 
[18] Maijamaa B, Nweze NO \& Bagudu HD. Coronavirus Disease (Covid-19) Is Global Recession Evitable? Jurnal Aplikasi Manajemen, Ekonomi dan Bisnis. 2020; 4(2): 71-7.

[19] Sigala M. Tourism and COVID-19: Impacts and implications for advancing and resetting industry and research. Journal of Business Research. 2020; 117: 312-321.

[20] Qantas cancels all international flights until March 2021, New Zealand (2020, July 14): New Zealand Herald. 2020.

[21] Nicola, M. et al. (2020) The socio-economic implications of the coronavirus pandemic (COVID-19): A review, International Journal of Surgery. June 2020, 78:185-1931

[22] Gössling S, Scott D, Hall CM. Pandemics, tourism and global change: A rapid assessment of COVID-19. Journal of Sustainable Tourism. 2020; 1-20.

[23] Chinazzi M, Davis J, Ajelli M, et al. The effect of travel restrictions on the spread of the 2019 novel coronavirus (COVID-19) outbreak. Science. 2020; 368(6489): 395-400.

[24] Skipworth H, Delbufalo E, Mena C. Logistics and procurement outsourcing in the healthcare sector: A comparative analysis. European Management Journal. 2020; 38(3): 518-32.

[25] Industrial Analytics Platform. How the pandemic disrupts global value chains. 2020.

[26] Sahu P. Closure of Universities Due to Coronavirus Disease 2019 (COVID-19): Impact on Education and Mental Health of Students and Academic Staff. Cureus. 2020; 12(4): e7541.

[27] Mohmmed AO, Khidhir B, Nazeer A, et al. Emergency remote teaching during Coronavirus pandemic: The current trend and future directive at Middle East College Oman. Innovative Infrastructure Solutions. 2020.

[28] Dill E, Fischer K, McMurtrie B, et al. As coronavirus spreads, the decision to move classes online is the first step. What comes next. The Chronicle of Higher Education. 2020.

[29] Timmis S, Broadfoot P, Sutherland R, et al. Rethinking assessment in a digital age: Opportunities, challenges and risks. British Educational Research Journal. 2015; 42(3): 454-76.

[30] Watson GR, Sottile J. Cheating in the digital age: Do students cheat more in online courses? Online Journal of Distance Learning Administration. 2009; 13(1).

[31] Cambridge International. Update for Cambridge schools on the June 2020 series - 20 August 2020.

[32] Gosens J, Jotzo F. China's post-COVID-19 stimulus: No Green New Deal in sight. Environmental Innovation and Societal Transitions. 2020; 36: 250-254.

[33] Griscom BW, Lomax G, Kroeger T, et al. We need both natural and energy solutions to stabilize our climate. Global Change Biology. 2019; 25(6): 1889-1890.

[34] Multidimensional Poverty in Pakistan (2016, June). UNDP. 2016; 67.

[35] Cheng SKW, Wong CW, Tsang J, Wong KC, et al. Psychological distress and negative appraisals in survivors of severe acute respiratory syndrome (SARS). Psychological Medicine. 2004; 34(7): 1187.

[36] Vieira SE. The health burden of pollution: The impact of prenatal exposure to air pollutants. International Journal of Chronic Obstructive Pulmonary Disease. 2015; 10: 1111-21.

[37] Guessoum SB, Lachal J, Radjack R, et al. Adolescent psychiatric disorders during the COVID-19 pandemic and lockdown. Psychiatry Research. 2020; 291: 113-264.

[38] Chen F, Ghosh A, Lin J, et al. 5-lipoxygenase pathway and its downstream cysteinyl leukotrienes as potential therapeutic targets for Alzheimer's disease. Brain, Behavior and Immunity. 2020; 88: 844-855.

[39] Yu X, Li C, Chen H, et al. Evaluate Air Pollution by Promethee Ranking in Yangtze River Delta of China. International Journal of Environmental Research and Public Health. 2020; 17(2): 587.

[40] World Health Organization (2018). Ambient air pollution: Health impacts.

[41] Sanders T, Liu Y, Buchner V, et al. Neurotoxic effects and biomarkers of lead exposure: A review. Reviews on Environmental Health. 2009; 24(1): 15.

[42] World Health Organization. European Centre for Environment and Health, WHO Regional Office for Europe. Review of evidence on health aspects of air pollution-REVIHAAP Project. Bonn, Germany. 2013; 309. 
[43] Cohen AJ, Brauer M, Burnett R, et al. Estimates and 25-year trends of the global burden of disease attributable to ambient air pollution: An analysis of data from the Global Burden of Diseases Study. Lancet. 2017; 389(10082): 1907-18.

[44] Assi MA, Hezmee MNM, Haron AW, et al. The detrimental effects of lead on human and animal health. Veterinary World. 2016; (6): 660-71.

[45] Newbold SC, Finnoff D, Thunstrom D, et al. Effects of Physical Distancing to Control COVID-19 on Public Health, the Economy and the Environment. Environmental \& Resource Economics. 2020; 1-25. 